\title{
Study on Development Sustainability of Atmospheric Environment in Northeast China by Rough Set and Entropy Weight Method
}

\author{
Yuangang Li ${ }^{1,+}$, Maohua Sun ${ }^{2,+}$, Guanghui Yuan ${ }^{3, *,+}\left(\mathbb{D}\right.$, Qi Zhou ${ }^{3,+}$ and Jinyue Liu ${ }^{4,+}$ \\ 1 Business School, Dalian University of Foreign Languages, Dalian 116044, China \\ 2 School of Foreign Language, Dalian Jiaotong University, Dalian 116028, China \\ 3 Fintech Research Institute \& School of Information Management and Engineering, Shanghai University of \\ Finance and Economics, Shanghai 200433, China \\ 4 Business School, University of Shanghai for Science and Technology, Shanghai 200093, China \\ * Correspondence: guanghuiyuan@outlook.com; Tel.: +86-21-6590-4028 \\ + All the authors contributed equally to this work.
}

Received: 25 May 2019; Accepted: 8 July 2019; Published: 11 July 2019

\begin{abstract}
In order to evaluate the atmospheric environment sustainability in the provinces of Northeast China, this paper has constructed a comprehensive evaluation model based on the rough set and entropy weight methods. This paper first constructs a Pressure-State-Response (PSR) model with a pressure layer, state layer and response layer, as well as an atmospheric environment evaluation system consisting of 17 indicators. Then, this paper obtains the weight of different indicators by using the rough set method and conducts equal-width discrete analysis and clustering analysis by using SPSS software. This paper has found that different discrete methods will end up with different reduction sets and multiple indicators sharing the same weight. Therefore, this paper has further introduced the entropy weight method based on the weight solution determined by rough sets and solved the attribute reduction sets of different layers by using the Rosetta software. Finally, this paper has further proved the rationality of this evaluation model for atmospheric environment sustainability by comparing the results with those of the entropy weight method alone and those of the rough set method alone. The results show that the sustainability level of the atmospheric environment in Northeast China provinces has first improved, and then worsened, with the atmospheric environment sustainability level reaching the highest level of 0.9275 in 2014, while dropping to the lowest level of 0.6027 in 2017. Therefore, future efforts should focus on reducing the pressure layer and expanding the response layer. Based on analysis of the above evaluation results, this paper has further offered recommendations and solutions for the improvement of atmospheric environment sustainability in the three provinces of Northeast China.
\end{abstract}

Keywords: PSR Model; rough set; entropy weight method; attribute reduction

\section{Introduction}

Sustainable development refers to "meeting the needs of contemporary people while at the same time sustaining the ability of future generations to meet their needs" [1]. In 1992, the Conference on Global Environment and Development in Rio de Janeiro adopted the Agenda of the Century [2]. After that, China also adopted The 21st Century Agenda of China. Both agendas have set sustainable development that "meets the current needs and pursuits of human without damaging the needs and pursuits of the future" as the goal of future economic development [2,3].

Sustainable development refers to development that meets the needs of the present without compromising the ability of future generations to meet their needs [4-6]. The atmosphere has significant 
implications to people's lives, which makes the topic of atmospheric environment sustainability one of the hottest discussions of today [7-9]. As a crucial part of human activities, the atmosphere and its quality directly impact the life and daily production of human beings. Since the origin of species, humans cannot survive without the air. The issue of air quality and safety is one of the key issues to humankind [10-12]. The Los Angeles photochemical smog episode in the 1940s, the serious sulfur dioxide pollution in Donora, Pennsylvania in October 1948, and the London smog incidents in December 1952, etc., all have warned us of the consequences of air pollution and unsustainable development [13-15].

As the world's second largest economy, China plays an increasingly important role in global economic development [16-18]. However, China is also a huge energy consumer [19-21]. China's energy consumption accounts for about $23 \%$ of world total consumption, and its coal consumption accounts for $59 \%$ of China's energy consumption, with an annual consumption of 4.64 billion tons. In 2018, China's consumption of coal, crude oil, natural gas and electricity increased by $1.0 \%, 6.5 \%$, $17.7 \%$ and $8.5 \%$, respectively [22].

Since the reform and opening up, some regions of China have paid too much attention to economic interests and neglected the protection of natural resources and the ecological environment, resulting in ecological imbalances and serious pollution, especially in provinces and cities that focus on heavy industry, where air pollution has become a common thing and has seriously damaged the health of the local population [23-25]. Such issues have not only brought dilemma to social development, but also developed new issues, in which ecological challenges are the most alarming [26-28].

With their vast land, rich fossil fuels resources such as coal, oil and natural gas, as well as their leading industrial foundation in the country, the three Northeastern provinces of China (Liaoning, Jilin and Heilongjiang) used to be the fastest-growing regions in modern China, known as the "Cradle of the Nation's Industry" [29,30]. However, in recent years, the three Northeastern provinces have experienced four key issues of high energy consumption, high resource dependence, high environmental degradation, and a high ratio of brain drain, and are now facing unprecedented energy and environmental crises. Such a phenomenon is called the "Northeast Phenomenon" [31-33].

Currently, the air pollution problem in Northeast China is also quite serious [34-36]. Although total emissions of $\mathrm{SO}_{2}$ and $\mathrm{NO}_{X}$ declined during the period between 2011 and 2017, $\mathrm{SO}_{2}$ and $\mathrm{NO}_{X}$ emissions are still $849,477.79$ tons and 1,270,006.47 tons in 2017, respectively (please refer to Figure 1) [37]. In this context, it is of great practical and theoretical significance to evaluate the development sustainability of the atmospheric environment in the Northeast region and explore effective air pollution control measures. It is necessary to study how to effectively find the weak points in atmospheric environment protection and take targeted improvement measures in provinces with lagging economic development to achieve sustainable development under the background of China's rapid economic growth.

When studying the sustainable development of the atmospheric environment, academic circles use the rough set method and the entropy weight method, respectively. For example, Lai et al. studied low carbon technology integration management using the rough set method. Based on a questionnaire survey and exploratory factor analysis results on the selected indexes, they implemented a rough set method to identify the weight of all the indexes. Their results showed that the constructed evaluation framework can properly reflect the integrity, and the rough set evaluation could well reflect the overall performance of low carbon project evaluation [38]. Xue et al. developed a fuzzy rough set algorithm to identify the spatial variability, driving forces, and uncertainties of the net ecosystem exchange of carbon between the temperate forests and the atmosphere. Their results showed the advantages of the new rough set algorithm and explained the most important variables for net ecosystem exchange in the northeastern United States [39]. Zhao et al. established a fuzzy comprehensive model based on entropy technology for air quality assessment. By improving the computing factors' weights with Entropy Weight Method, they used the new model to assess the air quality of Fuxin city, China. The results coincided with the objective air quality condition of Fuxin city greatly, which proved the effectiveness of the entropy weight method [40]. Chen et al. developed a hybrid approach, combining 
a land use regression model and the entropy weight method to estimate the PM2.5 concentrations on a national scale in China. They proved that the hybrid model could potentially provide more valid predictions than a commonly-used model. With $R^{2}=0.82$ and root mean square error of $4.6 \mu \mathrm{g} / \mathrm{m}^{3}$ [41]. Liu et al. estimated the relationship between urbanization and atmospheric environment security in Jinan City from 1996 to 2004 on the basis of the theory of environmental Kuznets curves. Employing the entropy method to determine the index weight, they constructed a comprehensive index system for urbanization and atmospheric environment security. They determined the main factors that influence the system to provide a basis for creating scientific urban development strategies and atmospheric environment protection measures [42].

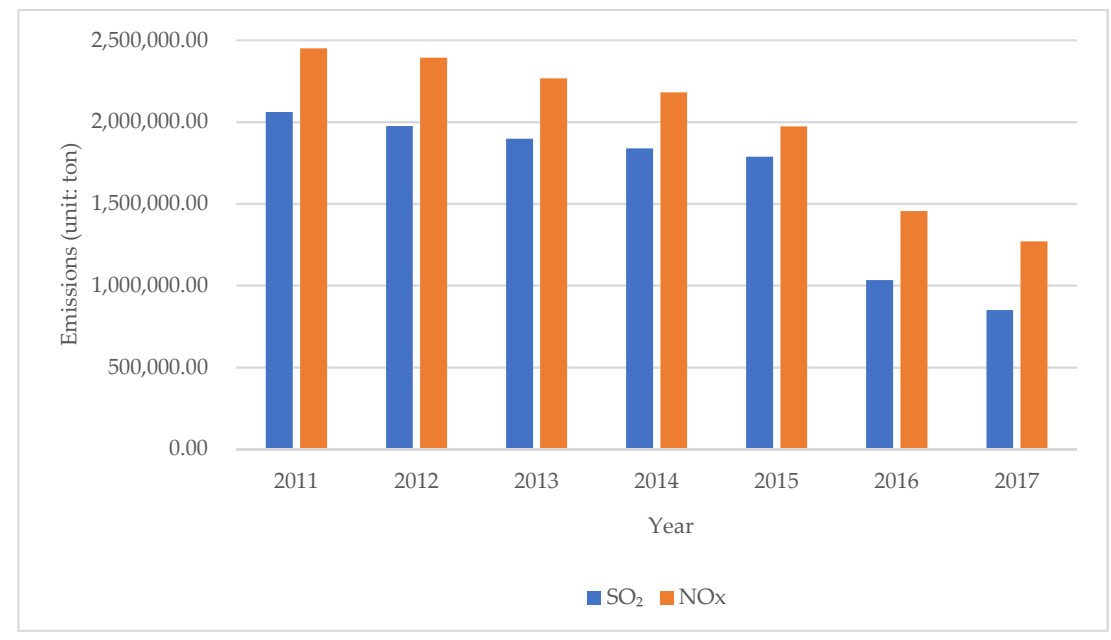

Figure 1. $\mathrm{SO}_{2}$ and NOx emissions in Northeast China from 2011 to 2017.

However, it is rare to combine the two methods to learn from each other. Based on rough set and entropy weight theory, this paper has determined the comprehensive weight by taking both the weight calculated by the attribute reduction set and the entropy weight into consideration, and that has improved the credibility and feasibility of the indicator weights. This paper has also compared experimental results by using different discrete methods, and found that the ranking of attribute values is basically consistent both before and after introducing the entropy weight, thus solving the problem of inconsistent results under different discrete methods and experimental methods. After comparing the results by this new method and by the method of determining the objective weights of the attributes based on the ideal structure optimization model, this paper has found that the rankings are basically the same, which further proves the rationality of this method. Finally, this paper has graded the indicator values into four levels (Excellent, Good, Medium, Poor) according to the actual level of atmospheric environment sustainability as well as previous studies on indicator grading. By determining the levels, this paper could obtain the level of sustainable development of each region based on a comprehensive indicator value.

\section{Materials and Methods}

\subsection{Modeling Basis}

Different from the traditional development concept solely based on economic development, sustainable development means balancing economic development with environmental protection and that the two things cannot be separated. When evaluating whether ecosystems are healthy, researchers often use the conceptual PSR Model based on the logic of "Pressure-State-Response" [43-46]. By analyzing the causal relationship inherent in the system, this model discovers the causal chain in the system, and then takes targeted adjustment measures to achieve system sustainability. When analyzing the relationship between humans and nature, this model believes that because of the pressure brought 
by human activities to the natural environment, the quantity of natural resources and some of the original properties of nature are changed, thus calling for society to take countermeasures through various environmental, economic and governance strategies. This process repeats over and over again, constituting the relationship between human beings and the natural environment. Whether the indicator system is reasonably constructed or not determines the accuracy of the evaluation results $[47,48]$. Therefore, it is necessary to select generalized and representative indicators as the evaluation indicators from a wide range of potential indicators. The following principles need to be followed: scientific, complete, principal components, and independent $[49,50]$. Regarding the principal components, this means that when selecting evaluation indicators, if the information given is sufficient, we should select as few indicators as possible and make sure that all indicators are representative.

\subsubsection{Establishment of the Indicator Layer for the PSR Model}

Pressure indicators refer to the environmental impact of human economic and social activities, such as the damage and disturbance to air quality caused by economic growth, social development, and emissions by various industries during their daily operation in the Northeast region. Therefore, the pressure layer refers to the collection of related indicators that cause damage and disturbance to the air quality and its sustainable development. [51]

State indicators refer to the environmental conditions and environmental changes within specific time periods, such as the consumption of coal, crude oil, and natural gas that affect the sustainable development of the Northeast region. Therefore, the state layer refers to the collection of economic indicators and energy consumption indicators generated by human life in economic activities. This layer includes indicators that are responsive assessments of human activities that can effectively describe the process of regional sustainable development [52].

Response indicators refer to how the society and individuals act to mitigate, stop, and prevent the negative impacts of human activities on the environment, as well as the remedial measures for ecological changes that have already occurred and hindered human survival and development, such as the waste treatment measures in the Northeast region. Therefore, the response layer refers to the collection of measures that society and individuals actively take action to mitigate, prevent, restore and prevent the negative impacts of human activities on the environment and remedy the environmental damage already caused [53].

Relieving pressure is at the core of the system; the state is the basis for the system to decide whether to respond; while response is the main way to achieve sustainable development. The three aspects of pressure, state and response interact with each other to form an organic feedback loop. Effective response behaviors would help to maintain the air quality of Northeast China at a good level. Otherwise, inappropriate response behaviors would cause the air quality of Northeast China to fall into a vicious circle.

\subsubsection{Construction of the Indicator System for the PSR Model}

Through empirical research, US economists Grossman and Krueger studied the relationship between the quality of the ecological environment and GDP per capita. They found that environmental pollution showed an upward trend with the growth of GDP per capita when the relative income was low, reached the peak at certain turning point when the countries entered the high-income stage, and then gradually declined with the growth of GDP per capita [54].

According to the above logic of causality, this paper has allocated various factors into the pressure layer, the state layer and the response layer respectively. Drawing on existing research $[51,55,56]$ and combining the characteristics of the three provinces, we selected 17 indicators including core and supplementary indicators based on the data of air quality and GDP per capita of the Northeastern provinces from 2009 to 2017 to construct the PSR Model [57]. This indicator system is complete and independent with a principal component and accurately reflects the sustainability level of the atmospheric environment in Northeast China, as shown in Table 1. 
Table 1. The indicators in the Pressure-State-Response (PSR) Model for Northeast China atmospheric environment sustainability measurement and their standardized values from 2009 to 2017.

\begin{tabular}{|c|c|c|c|c|c|c|c|c|c|c|}
\hline The Element Layer & The Indicator Layer & 2009 & 2010 & 2011 & 2012 & 2013 & 2014 & 2015 & 2016 & 2017 \\
\hline \multirow{6}{*}{ The Pressure Layer } & $\mathrm{SO}_{2}$ & 0.060 & 0.061 & 0.000 & 0.015 & 0.063 & 0.095 & 0.126 & 0.352 & 0.437 \\
\hline & Nitric Oxide & 0.004 & 0.177 & 0.000 & 0.004 & 0.041 & 0.068 & 0.177 & 0.311 & 0.477 \\
\hline & Smoke (Dust) & 0.111 & 0.093 & 0.174 & 0.119 & 0.090 & 0.000 & 0.188 & 0.437 & 0.493 \\
\hline & Oil Reserves & 0.000 & 0.000 & 0.060 & 0.080 & 0.132 & 0.168 & 0.192 & 0.218 & 0.218 \\
\hline & Natural Gas Reserves & 0.084 & 0.000 & 0.034 & 0.053 & 0.073 & 0.079 & 0.098 & 0.110 & 0.079 \\
\hline & Coal Reserves & 0.000 & 0.109 & 0.951 & 0.966 & 1.000 & 0.903 & 0.971 & 0.882 & 1.000 \\
\hline \multirow{8}{*}{$\begin{array}{l}\text { The } \\
\text { State } \\
\text { Layer }\end{array}$} & Regional GDP (Hundred Million RMB) & 0.539 & 0.651 & 0.791 & 0.861 & 0.909 & 0.946 & 0.948 & 0.967 & 1.000 \\
\hline & $\begin{array}{l}\text { Value Added of the Secondary Industry } \\
\text { (Hundred Million RMB) }\end{array}$ & 0.671 & 0.831 & 0.987 & 1.000 & 0.968 & 0.918 & 0.793 & 0.727 & 0.671 \\
\hline & $\begin{array}{l}\text { Value Added of the Service Industry } \\
\text { (Hundred Million RMB) }\end{array}$ & 0.377 & 0.453 & 0.552 & 0.623 & 0.690 & 0.775 & 0.861 & 0.936 & 1.000 \\
\hline & $\begin{array}{l}\text { Industrial Value Added (Hundred } \\
\text { Million RMB) }\end{array}$ & 0.675 & 0.844 & 0.999 & 1.000 & 0.971 & 0.912 & 0.772 & 0.694 & 0.633 \\
\hline & GDP per capita (RMB) & 0.535 & 0.646 & 0.783 & 0.852 & 0.899 & 0.936 & 0.941 & 0.965 & 1.000 \\
\hline & Coal Consumption (Ten Thousand Tons) & 0.786 & 0.869 & 0.939 & 0.994 & 0.944 & 0.967 & 0.956 & 0.999 & 1.000 \\
\hline & $\begin{array}{l}\text { Crude Oil Consumption } \\
\text { (Ten Thousand Tons) }\end{array}$ & 0.933 & 0.952 & 0.996 & 0.980 & 0.962 & 0.969 & 0.960 & 1.000 & 0.973 \\
\hline & $\begin{array}{c}\text { Natural Gas Consumption (Hundred } \\
\text { Million Cubic Meters) }\end{array}$ & 0.012 & 0.000 & 0.135 & 0.464 & 0.598 & 0.686 & 0.727 & 1.000 & 0.792 \\
\hline \multirow{3}{*}{ The Response Layer } & $\begin{array}{l}\text { Investment in Industrial Pollution } \\
\text { Control (Ten Thousand RMB) }\end{array}$ & 0.479 & 0.238 & 0.487 & 0.189 & 1.000 & 0.858 & 0.934 & 0.840 & 0.440 \\
\hline & $\begin{array}{c}\text { Investment in Waste Gas Control (Ten } \\
\text { Thousand RMB) }\end{array}$ & 0.271 & 0.091 & 0.422 & 0.149 & 1.000 & 0.871 & 0.730 & 0.835 & 0.373 \\
\hline & $\begin{array}{c}\text { Local Fiscal Expenditure on } \\
\text { Environmental Protection (Hundred } \\
\text { Million RMB) }\end{array}$ & 0.000 & 0.223 & 0.248 & 0.341 & 0.423 & 0.391 & 0.719 & 0.405 & 1.000 \\
\hline
\end{tabular}




\subsection{Evaluation Model on Atmospheric Environment Sustainability}

\subsubsection{Basic Concept of the Model}

First, this paper determines the weight of each layer by using the rough set and entropy weight methods. Because the two methods are both objective methods for determining weights, the combination of the two has taken both the importance of each attribute to decision-making and the influence of the information quantity within each attribute on decision-making into consideration, thus achieving more precise weights [58-61]. Secondly, by assuming the weights of element layers, this paper has constructed a comprehensive evaluation model on atmospheric environment sustainability to obtain the sustainability indicator value. At last, this paper has ranked the objects under assessment based on the indicator values, and respectively determined each object's influence on the sustainability level.

\subsubsection{Evaluation Steps}

1. Standardize the raw data. Due to different properties of the evaluation indicators, the original data are in different dimensions and orders of magnitude. In order to eliminate the influence of difference in dimensions and ensure the comparability of data as well as the feasibility of the decision-making results, it is necessary to properly standardize the original data. Suppose there are $N$ evaluation objects, $M$ evaluation indicators, the evaluation value of the indicators is expressed as $m_{i j}^{i}(i \in N, J \in M)$, and the standardized indicator value is written as $m_{i j}^{i}$. It can be concluded from the relevant literature that for benefit attributes, the larger the indicator value, the better; while for cost attributes, the smaller the indicator value, the better [62,63]. In this paper, the indicators in the state layer and the response layer are benefit attributes, while the indicators in the pressure layer are cost attributes. Then we have:

$$
\begin{aligned}
& m_{i j}=\frac{m_{i j}^{\prime}-\min _{i \in N}\left\{m_{i j}^{\prime}\right\}}{\min _{i \in N}\left\{m_{i j}^{\prime}\right\}-\max _{i \in N}\left\{m_{i j}^{\prime}\right\}} \\
& m_{i j}=\frac{\max _{i \in N}\left\{m_{i j}^{\prime}\right\}-m_{i j}^{\prime}}{\max _{i \in N}\left\{m_{i j}^{\prime}\right\}-\min _{i \in N}\left\{m_{i j}^{\prime}\right\}}
\end{aligned}
$$

2. Determine the Decision Weights. When rough sets are used to process data, the general approach is to determine the indicator weights based on the importance of various attributes [64,65]. However, this method is flawed. The reduction set of attributes refers to the smallest set of attributes whose number is greater than zero while division is the same with the original data set. The intersection of all reduction sets is called the core attribute. It can be found by data analysis that when the core attribute does not exist, the indicator weights based on the importance of various attributes all equal to zero, which is in contradiction with the fact. When the core attribute does not exist, the attributes in all the reduction sets are relatively necessary attributes. It can be learned from the literature that the importance of each attribute can be determined by the ratio of the number of occurrences of the attribute in the reduction sets to the total number of reduction sets $[66,67]$.

Let $H$ be the total number of reduction sets. $H$ is the number of reduction sets that contain the relatively necessary attribute $L_{j}$, then the weight of $L_{j}$ is $X_{L_{J}}^{*}=g / G$, which can be normalized as:

$$
X_{L_{J}}=\left(X_{L_{J}}^{1}+X_{L_{J}}^{2}\right) / 2
$$

Although the above method can determine the weights of relatively necessary attributes, on the one hand, because the data processed by this method is discrete, different attribute discretization methods would result in different reduction sets, thus obtaining inconsistent attribute weights; on the other hand, it happens that some attributes would have the same weights as calculated by Formula (3). Therefore, it can be seen that this method is inadequate to properly calculate the weights of relatively necessary attributes. 
In order to make up for the shortcomings of the above two methods, this paper has integrated the entropy weight method with the attribute reduction set method for weight calculation. The entropy weight method is an objective weighting method based on normalization matrix calculation and is not suitable for discrete data $[68,69]$. The entropy weight method analyzes the influence of indicator variation on the weight $[70,71]$, while the attribute reduction set method examines the dependence of decision attributes on conditional attributes [72-74]. By combining the weights obtained by both methods, this paper has comprehensively considered the importance of each attribute to decision-making and the influence of information quantity within each attribute on decision-making, thus determining the weight of attributes based on two aspects and making up for the shortcomings of the attribute reduction set method in weight determination.

According to existing literature, the entropy weight of indicator $L_{j}$ is [75]:

$$
X_{L_{J}}^{2}=\left(1+s \sum_{i=1}^{N} \ln t_{i_{j}}\right) /\left(M+s \sum_{j=1}^{M} \sum_{i=1}^{N} t_{i_{j}} \ln t_{i_{j}}\right)
$$

in which $s=1 / \ln N, t_{i_{j}}=m_{i_{j}} / \sum_{i=1}^{N} m_{i_{j}}$. Assume that when $t_{i_{j}}=0, h_{i_{j}} \ln h_{i_{j}}=0$.

By combining the weight obtained from the attribute reduction set method $\left(X_{L_{J}}^{1}\right)$ and the entropy weight $\left(X_{L_{J}}^{2}\right)$, this paper has obtained the new weight for indicator $L_{j}\left(X_{L_{J}}\right)$, which comprehensively considers the importance of the attribute itself and its information quantity to decision-making, and therefore makes the weighting more reasonable.

3. Calculate the Comprehensive Evaluation Value. Suppose the importance weights of the pressure layer, the state layer and the response layer in sustainable development are $\omega, \psi, \xi$, respectively. Then, the comprehensive value can be expressed as:

$$
Z_{i}=\omega \sum_{j=1}^{M_{1}} m_{i_{j}} X_{L_{j}}+\psi \sum_{j=M_{1}+1}^{M_{2}} m_{i_{j}} X_{L_{j}}+\xi \sum_{j=M_{2}+1}^{M_{3}} m_{L_{j}} X_{L_{j}}
$$

where $M_{1}, M_{2}$, and $M_{3}$ respectively stand for the number of indicators in the pressure layer, the state layer and the response layer; $\omega, \psi, \xi$ are determined by the weighting method based on standard deviation, i.e., by Formula (7) [15]; $e_{i_{j}}$ is the indicator value of the pressure layer, the state layer and the response layer; $\bar{e}_{j}$ is the mean value of the indicator values.

$$
X_{j}=\sqrt{\sum_{i=1}^{N}\left(e_{i_{j}}-\bar{e}_{j}\right)^{2} /(N-1)}, X_{j}=X_{j} / \sum_{j=1}^{3} X_{j}
$$

Based on previous research results on the development sustainability level and the actual situation of sustainable development of the atmospheric environment [76,77], this paper has graded sustainability indicator values into four levels (Excellent, Good, Medium, Poor). When the sustainability indicator value is no lower than $0.9(Z \geq 0.9)$, its level of sustainable development is Excellent, indicating a high level of sustainability of the atmospheric environment in various aspects including the economic, environmental and social aspects. When $0.75<Z<0.9$, its level of sustainable development is Good; when $0.6<Z \leq 0.75$, its level of sustainable development is Medium, which indicates that the sustainability of the atmospheric environment in this region has improved but this improvement is not prominent. When $Z \leq 0.6$, its level of sustainable development is Poor, indicating a low level of sustainability of the atmospheric environment in this region which requires significant improvement efforts. 


\section{Results}

\subsection{Standardize the Evaluation Indicator}

By standardizing the air quality data of the three Northeastern provinces from 2009 to 2017 according to Formulas (1) and (2), this paper has obtained the standardized values of various indicators (as shown in Table 1).

This paper has adopted the rough set method to process discrete data and used SPSS software to perform equal-width discrete analysis and clustering analysis on the data [20]. The equal-width discrete algorithm is a typical unsupervised discretization method, which equally divides the standardized data between $[0,1]$ into four intervals: $(0.9,1.0),(0.65,0.9),(0.5,0.65)$, and $(0,0.5)$. Four discrete values are selected for these intervals: 4, 3, 2, and 1, corresponding to Excellent, Good, Medium, and Poor, respectively. Clustering analysis is used to obtain decision attributes, which are divided into four categories according to the conditional attributes, and the decision information system is eventually determined as shown in Table 2 below:

Table 2. Decision table of the PSR Model.

\begin{tabular}{|c|c|c|c|c|c|c|c|c|}
\hline $\begin{array}{l}\text { The Element } \\
\text { Layer }\end{array}$ & The Indicator Layer & 2011 & 2012 & 2013 & 2014 & 2015 & 2016 & 2017 \\
\hline \multirow{6}{*}{$\begin{array}{l}\text { The Pressure } \\
\text { Layer }\end{array}$} & $\mathrm{SO}_{2}$ & 1 & 1 & 1 & 1 & 1 & 2 & 2 \\
\hline & Nitric Oxide & 1 & 1 & 1 & 1 & 1 & 2 & 2 \\
\hline & Smoke (Dust) & 1 & 1 & 1 & 1 & 1 & 2 & 2 \\
\hline & Oil Reserves & 1 & 1 & 1 & 1 & 1 & 1 & 1 \\
\hline & Natural Gas Reserves & 1 & 1 & 1 & 1 & 1 & 1 & 1 \\
\hline & Coal Reserves & 4 & 4 & 4 & 4 & 4 & 4 & 4 \\
\hline \multirow{8}{*}{$\begin{array}{l}\text { The State } \\
\text { Layer }\end{array}$} & $\begin{array}{c}\text { Regional GDP } \\
\text { (Hundred Million RMB) }\end{array}$ & 4 & 4 & 4 & 4 & 4 & 4 & 4 \\
\hline & $\begin{array}{l}\text { Value Added of the Secondary } \\
\text { Industry (Hundred Million RMB) }\end{array}$ & 4 & 4 & 4 & 4 & 4 & 3 & 3 \\
\hline & $\begin{array}{l}\text { Value Added of the Service Industry } \\
\text { (Hundred Million RMB) }\end{array}$ & 3 & 3 & 3 & 4 & 4 & 4 & 4 \\
\hline & $\begin{array}{l}\text { Industrial Value Added } \\
\text { (Hundred Million RMB) }\end{array}$ & 4 & 4 & 4 & 4 & 4 & 3 & 3 \\
\hline & GDP per capita (RMB) & 4 & 4 & 4 & 4 & 4 & 4 & 4 \\
\hline & $\begin{array}{l}\text { Coal Consumption } \\
\text { (Ten Thousand Tons) }\end{array}$ & 4 & 4 & 4 & 4 & 4 & 4 & 4 \\
\hline & $\begin{array}{l}\text { Crude Oil Consumption } \\
\text { (Ten Thousand Tons) }\end{array}$ & 4 & 4 & 4 & 4 & 4 & 4 & 4 \\
\hline & $\begin{array}{l}\text { Natural Gas Consumption (Hundred } \\
\text { Million Cubic Meters) }\end{array}$ & 1 & 2 & 3 & 3 & 3 & 4 & 4 \\
\hline \multirow{3}{*}{$\begin{array}{l}\text { The Response } \\
\text { Layer }\end{array}$} & $\begin{array}{l}\text { Investment in Industrial Pollution } \\
\text { Control (Ten Thousand RMB) }\end{array}$ & 2 & 1 & 4 & 4 & 4 & 4 & 2 \\
\hline & $\begin{array}{l}\text { Investment in Waste Gas Control } \\
\text { (Ten Thousand RMB) }\end{array}$ & 2 & 1 & 4 & 4 & 3 & 4 & 2 \\
\hline & $\begin{array}{c}\text { Local Fiscal Expenditure on } \\
\text { Environmental Protection (Hundred } \\
\text { Million RMB) }\end{array}$ & 1 & 2 & 2 & 2 & 3 & 2 & 4 \\
\hline
\end{tabular}

Table 2 shows the change in the discrete values of the indicators in the three Northeastern provinces from 2011 to 2017 . It can be seen that although the values of the pressure layer elements $\left(\mathrm{SO}_{2}\right.$, Nitric Oxide, Smoke/Dust) have shown an improvement trend, they still belong to the Medium Level. Therefore, it can be concluded that the air quality of Northeast China is still quite poor, and it is necessary to look for a sustainable development plan for the Northeast region regarding the 
atmospheric environment. The reserves of oil, natural gas and coal resources are generally stable, of which oil and natural gas are relatively scarce, while coal reserves are relatively abundant. On the other hand, it can be seen by analysis of the elements of the state layer that the Northeast region has not only maintained excellent regional GDP, but the industrial structure of the three Northeast provinces is also undergoing certain changes. For example, the added value of the secondary industry has decreased compared with that of the service industry; the growth of the industry has slowed down but the regional GDP per capita has still remained at an excellent level. Overall, the consumption of coal and oil is still quite high, and the consumption of natural gas is growing. The investment in industrial pollution control and waste gas control has first increased but later decreased, while the local fiscal expenditure on environmental protection has shown an increasing trend. Based on the above table, we could clearly understand the changes in the relevant factors that influence the air quality sustainability of the Northeast region as well as their values in different time periods. It can be seen that the three Northeast provinces have made efforts to improve their air quality in recent years and have achieved certain results. However, there is still a long way to go before these provinces have accomplished a true transformation and upgrade.

\subsection{Determine the Weights}

Attribute reduction refers to selecting the minimum condition subset while ensuring an unchanged correlation coefficient as the decision system so as to determine the condition attributes in the decision rule. By using Table 2 and the Rosetta software, this paper has obtained the attribute reduction set of each layer.

The Attribute Reduction Set of the Pressure Layer:

Heilongjiang: $\left\{a_{2}, a_{6}\right\},\left\{a_{1}, a_{6}\right\},\left\{a_{3}, a_{6}\right\}$;

Jilin: $\left\{a_{1}, a_{3}, a_{6}\right\},\left\{a_{2}, a_{3}, a_{6}\right\}$;

Liaoning: $\left\{a_{1}, a_{3}, a_{5}, a_{6}\right\},\left\{a_{2}, a_{3}, a_{5}, a_{6}\right\}$.

The Attribute Reduction Set of the State Layer:

Heilongjiang: $\left\{b_{3}, b_{4}, b_{5}, b_{8}\right\},\left\{b_{1}, b_{3}, b_{4}, b_{8}\right\},\left\{b_{2}, b_{3}, b_{5}, b_{8}\right\},\left\{b_{1}, b_{2}, b_{3}, b_{8}\right\}$;

Jilin: $\left\{b_{3}, b_{4}, b_{8}\right\},\left\{b_{2}, b_{3}, b_{5}, b_{8}\right\},\left\{b_{1}, b_{2}, b_{3}, b_{8}\right\}$;

Liaoning: $\left\{b_{2}, b_{3}, b_{8}\right\},\left\{b_{3}, b_{4}, b_{8}\right\}$.

The Attribute Reduction Set of the Response Layer:

Heilongjiang: $\left\{c_{1}, c_{3}\right\},\left\{c_{2}, c_{3}\right\}$;

Jilin: $\left\{c_{1}, c_{2}, c_{3}\right\}$;

Liaoning: $\left\{c_{1}, c_{2}, c_{3}\right\}$.

Based on the attribute reduction set of various indicator layers and Formula (3), this paper has obtained the relatively necessary attribute weight $X_{L_{J}}^{1}$; based on Formulas (4) and (5) and Table 1, this paper has obtained the entropy weight of each indicator layer $X_{L_{J}}^{2}$ and the new weight $X_{L_{J}}$. The calculation results are shown in Table 3. Different from subjective methods that rely on expert experience and lack objectivity and objective methods with poor explanatory power, the method in this paper uses the rough set method to explore the internal relationship within the experimental data so that the weight obtained by this method could demonstrate the information quantity within each attribute. In this way, it can be ensured that the indicators selected could reflect most of the original information, thus achieving more effective and objective results. Moreover, during data analysis, this paper has performed equal-width discrete analysis, thus preventing the potential problem of inconsistent weighting under different discretization methods. By combining the entropy weight method with the attribute reduction set method, this paper has made up for the shortcomings of the reduction set method and obtained more reasonable weighting results. 
Table 3. The weights of various indicators.

\begin{tabular}{|c|c|c|c|c|}
\hline $\begin{array}{c}\text { The Element } \\
\text { Layer }\end{array}$ & Indicator & $\begin{array}{c}\text { Entropy-Based } \\
\text { Weight } X_{L j}^{1}\end{array}$ & Rough Weight $X_{L j}^{2}$ & $\begin{array}{c}\text { Average Weight } \\
X_{L j}\end{array}$ \\
\hline \multirow{6}{*}{ The Pressure Layer } & a1 & 0.2409 & 0.1667 & 0.2038 \\
\hline & a2 & 0.2862 & 0.1667 & 0.2264 \\
\hline & a3 & 0.1533 & 0.1667 & 0.1600 \\
\hline & a4 & 0.1525 & 0.0000 & 0.0763 \\
\hline & a5 & 0.0753 & 0.0000 & 0.0376 \\
\hline & a6 & 0.0919 & 0.5000 & 0.2959 \\
\hline \multirow{8}{*}{ The State Layer } & $\mathrm{b} 1$ & 0.0375 & 0.1250 & 0.0813 \\
\hline & b2 & 0.0256 & 0.1250 & 0.0753 \\
\hline & b3 & 0.0995 & 0.2500 & 0.1747 \\
\hline & $\mathrm{b} 4$ & 0.0311 & 0.1250 & 0.0780 \\
\hline & b5 & 0.0380 & 0.1250 & 0.0815 \\
\hline & b6 & 0.0059 & 0.0000 & 0.0029 \\
\hline & b7 & 0.0005 & 0.0000 & 0.0002 \\
\hline & $\mathrm{b} 8$ & 0.7619 & 0.2500 & 0.5060 \\
\hline \multirow{3}{*}{$\begin{array}{c}\text { The Response } \\
\text { Layer }\end{array}$} & $\mathrm{c} 1$ & 0.2158 & 0.2500 & 0.2329 \\
\hline & c2 & 0.3568 & 0.2500 & 0.3034 \\
\hline & c3 & 0.4274 & 0.5000 & 0.4637 \\
\hline
\end{tabular}

\subsection{Calculate the Comprehensive Evaluation Value}

Based on Table 1, Table 3, and Formula (6), this paper has obtained the attribute values and sustainability levels of each indicator layer as shown in Table 4 below. From Table 4 , it can be seen that the sustainability levels from 2009 to 2017 are ranked as: $Z_{2014}>Z_{2013}>Z_{2015}>Z_{2011}>Z_{2012}>$ $Z_{2017}>Z_{2009}>Z_{2010}>Z_{2016}$.

Table 4. The comprehensive management and sustainability level obtained by the PSR Model.

\begin{tabular}{cccccc}
\hline Year & $\boldsymbol{p}$ Value & $\boldsymbol{S}$ Value & $\boldsymbol{R}$ Value & Sustainable Value $\boldsymbol{Z}$ & Level \\
\hline 2009 & 0.1677 & 0.0023 & 0.0273 & 0.5810 & Poor \\
\hline 2010 & 0.1549 & 0.0028 & 0.0189 & 0.5455 & Poor \\
\hline 2011 & 0.1672 & 0.0034 & 0.0155 & 0.7287 & Medium \\
\hline 2012 & 0.1576 & 0.0037 & 0.0151 & 0.6777 & Medium \\
\hline 2013 & 0.1541 & 0.0041 & 0.0397 & 0.8009 & Good \\
\hline 2014 & 0.1719 & 0.0043 & 0.0617 & 0.9275 & Excellent \\
\hline 2015 & 0.1581 & 0.0043 & 0.0332 & 0.7723 & Good \\
\hline 2016 & 0.0997 & 0.0037 & 0.0298 & 0.5459 & Poor \\
\hline 2017 & 0.0850 & 0.0039 & 0.0266 & 0.6027 & Medium \\
\hline
\end{tabular}

\section{Discussion}

By comparing the above method with the entropy weight method and the rough set method alone, we can obtain the rationality of the method adopted in this paper, i.e., introducing the entropy weight method based on the rough set method to construct a sustainable development model. The calculation results of the three different methods for Northeast China as a whole are shown in Table 5 below (Please refer to Appendix A for the calculation results of each province in Northeast China.): 
Table 5. Comparison of comprehensive values calculated by different methods for Northeast China.

\begin{tabular}{|c|c|c|c|c|}
\hline $\begin{array}{l}\text { The Element } \\
\text { Layer }\end{array}$ & Year & $\begin{array}{c}\text { The Entropy } \\
\text { Weight Method }\end{array}$ & $\begin{array}{c}\text { The Rough Set } \\
\text { Method }\end{array}$ & $\begin{array}{l}\text { Rough Set + Entropy } \\
\text { Weight Method }\end{array}$ \\
\hline \multirow{9}{*}{ The Pressure Layer } & 2009 & 0.7090 & 0.6882 & 0.7092 \\
\hline & 2010 & 0.5728 & 0.7016 & 0.6364 \\
\hline & 2011 & 0.6807 & 0.7199 & 0.7239 \\
\hline & 2012 & 0.5878 & 0.6831 & 0.6473 \\
\hline & 2013 & 0.6439 & 0.6915 & 0.6624 \\
\hline & 2014 & 0.6928 & 0.7776 & 0.7033 \\
\hline & 2015 & 0.6724 & 0.7164 & 0.6486 \\
\hline & 2016 & 0.4083 & 0.4420 & 0.4418 \\
\hline & 2017 & 0.3944 & 0.3380 & 0.3233 \\
\hline \multirow{9}{*}{ The State Layer } & 2009 & 0.3063 & 0.3587 & 0.2879 \\
\hline & 2010 & 0.3195 & 0.2727 & 0.2727 \\
\hline & 2011 & 0.4249 & 0.4063 & 0.4061 \\
\hline & 2012 & 0.4159 & 0.4477 & 0.4270 \\
\hline & 2013 & 0.4996 & 0.4999 & 0.4497 \\
\hline & 2014 & 0.4640 & 0.4757 & 0.4574 \\
\hline & 2015 & 0.4876 & 0.5377 & 0.4659 \\
\hline & 2016 & 0.3623 & 0.4488 & 0.4274 \\
\hline & 2017 & 0.4944 & 0.5168 & 0.4596 \\
\hline \multirow{9}{*}{$\begin{array}{c}\text { The Response } \\
\text { Layer }\end{array}$} & 2009 & 0.5036 & 0.4075 & 0.4039 \\
\hline & 2010 & 0.2560 & 0.2846 & 0.2557 \\
\hline & 2011 & 0.3749 & 0.2587 & 0.2562 \\
\hline & 2012 & 0.2300 & 0.2195 & 0.2389 \\
\hline & 2013 & 0.7124 & 0.6638 & 0.6034 \\
\hline & 2014 & 0.8988 & 0.7609 & 0.8225 \\
\hline & 2015 & 0.5120 & 0.4447 & 0.4475 \\
\hline & 2016 & 0.5429 & 0.5613 & 0.4860 \\
\hline & 2017 & 0.3794 & 0.3243 & 0.3577 \\
\hline \multirow{9}{*}{$\begin{array}{c}\text { The Sustainable } \\
\text { Layer }\end{array}$} & 2009 & 0.3349 & 0.4542 & 0.4180 \\
\hline & 2010 & 0.3781 & 0.5273 & 0.4273 \\
\hline & 2011 & 0.3898 & 0.4698 & 0.5072 \\
\hline & 2012 & 0.4127 & 0.5105 & 0.5143 \\
\hline & 2013 & 0.3490 & 0.5667 & 0.5460 \\
\hline & 2014 & 0.5182 & 0.6392 & 0.6799 \\
\hline & 2015 & 0.4124 & 0.5746 & 0.5630 \\
\hline & 2016 & 0.5036 & 0.4915 & 0.4454 \\
\hline & 2017 & 0.4663 & 0.4455 & 0.4544 \\
\hline
\end{tabular}

Different discrete methods would lead to different ranking results, especially the ranking of sustainability indicators. By the entropy weight method, the year of 2009 had the lowest sustainability value of 0.3349 ; while by the rough set method, the year of 2017 had the lowest sustainability value of 0.4455 , which indicates large differences in the sustainability evaluation result by different weighting methods, and that the choice of weighting methods directly affects the accuracy of the evaluation. However, if the entropy weight method is further introduced based on the rough set method, the result obtained is consistent with the result obtained through the original Method, as shown in Figure 2 below. According to the result, in Northeast China, the same year 2009 had the lowest 
sustainability level for atmospheric environment, with an indicator value of 0.4180; while the year 2014 has the best sustainability level with an indicator value of 0.6799 . This proves that by introducing the entropy weight method, this paper has solved the issue of inconsistent results by different weighting methods. The rough set method categorizes the data based on attributes and examines the degree of approximation by finding the upper and lower approximations and finding the positive domain. In the assessment of sustainable development of the atmospheric environment in the Northeast region, the rough set method can be used to draw rough conclusions. However, because different weighting methods would lead to different results, this would have a great impact on the accuracy of the data as well as the final conclusion. The entropy weight method is an objective weighting method which only depends on the discreteness of the data. The entropy value can be used to determine the discrete degree of the indicator, and thereby obtain the weight of the indicator in overall comprehensive evaluation. Thanks to this feature of the entropy weight method, the accuracy of the evaluation result can be effectively improved so as to make up for the flaw of the rough set method that different weighting methods would lead to different conclusions [78-80].

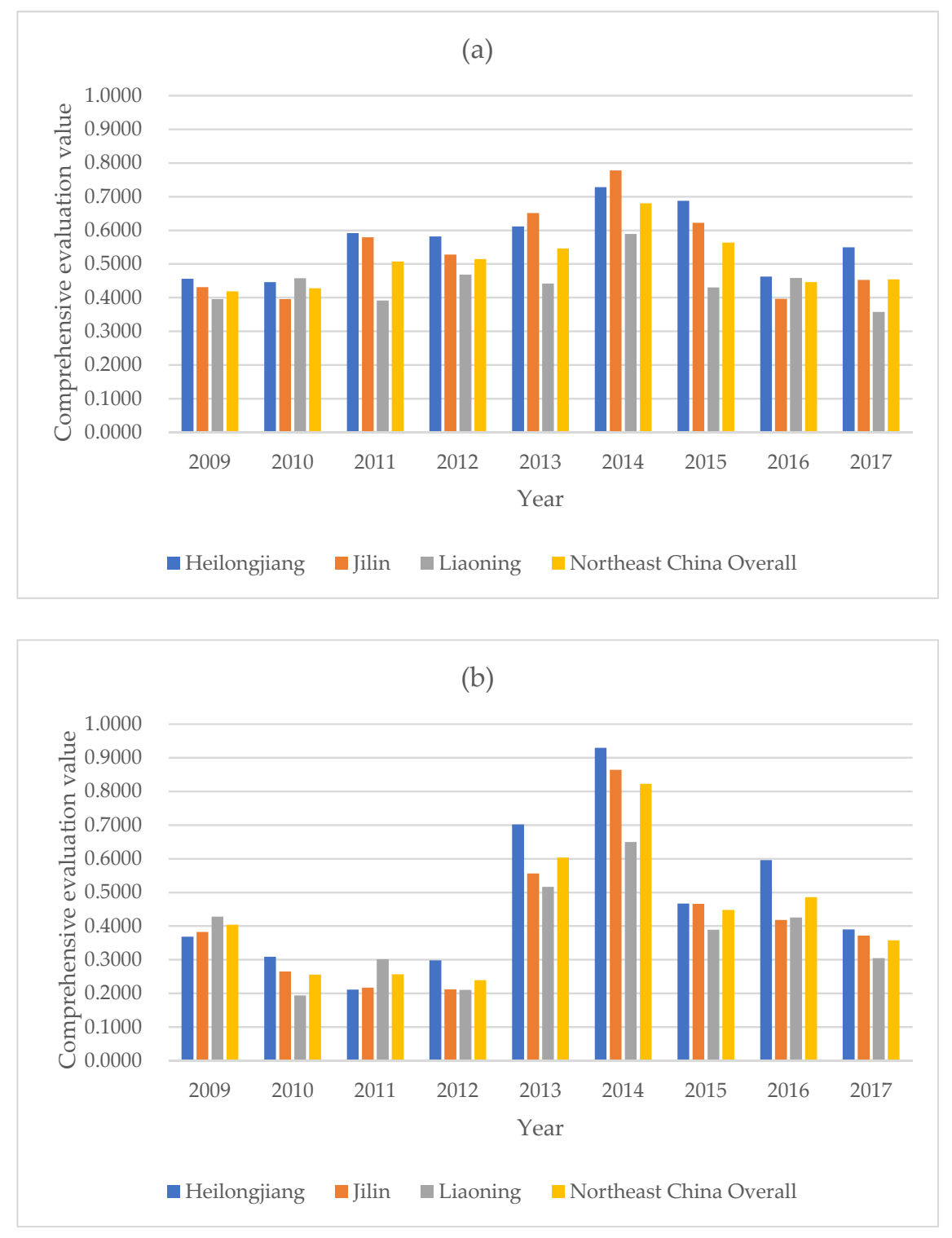

Figure 2. Calculation results of the rough set plus entropy weight method for Northeast China: (a) Results of the sustainable layer; (b) Results of the response layer. 
From Table 5, we could learn the sustainability level of the atmospheric environment in Northeast China: the state layer and the response layer have both shown an upward trend, while the pressure layer has shown a downtrend. Now we can perform a targeted analysis based on the different trends of various indicator layers:

1. Pressure Indicators: it can be seen from the comprehensive value of the pressure indicators that 2014 and 2015 have the best performance, but there has been a downtrend in recent years, with a record low in 2017, which is probably due to increasing demands for resources with the increase of population pressure. The Northeast region is the industrial heartland of China. Back in 2016, the National People's Congress and Chinese People's Political Consultative Conference reaffirmed the policy of "revitalizing the old industrial base in Northeast China", which probably had led to a growing demand for resources in this region. In addition, the Northeast region faces severe cold during winters. The strong demand for heating and large consumption of coal would cause the environmental quality to further deteriorate.

2. State Indicators: the indicators of the state layer have generally shown an upward trend, indicating an overall improvement in resource utilization rate in the Northeast region with growing environmental awareness. In addition, the state layer indicators have reflected the fact that in the wave of globalization, the industrial development of the Northeast region has had a great impact on the atmospheric environment sustainability. As the cradle of China's core industry, while it continues to develop its industry, the Northeast region should also pay attention to the reuse of resources and increase investment in clean energy development.

3. Response Indicators: the indicators of the response layer have generally shown a downward trend. The investment reached its peak in 2014, and according to various indicators, the sustainability level of the Northeast provinces also reached its best in 2014, indicating that enterprises and local government are working towards a correct direction in terms of environmental protection investment. The Northeast provinces could see more achievements if they increase their investment in environmental protection.

4. Sustainability Indicators: there have been large fluctuations in the sustainability indicators, which are mainly affected by the air quality protection investment by enterprises and the local government, the promotion of clean energy such as natural gas, and the environmental awareness of people. This indicates that achieving sustainable development is the common responsibility of everyone in our society. Individuals, enterprises and the government should all establish a sense of responsibility and strengthen their understanding of sustainable development concepts, thus promoting the sustainable development of the Northeastern provinces.

It can also be found that Heilongjiang Province has done the best in the sustainable development of the atmospheric environment during the research period. On the whole, the main reasons are:

(1) Heilongiiang strictly abides by the state's laws, regulations and action guidelines on air pollution control, and has formulated a series of sustainable development policies for atmospheric environment with local characteristics and specificity. It has issued and released "Implementation Rules of Air Pollution Prevention Action Plan in Heilongjiang" [81], "Special Action Plan for Air Pollution Prevention and Control in Heilongjiang Province, 2016-2018" [82], and "Air Pollution Prevention and Control Regulations of Heilongiiang Province" [83], etc. These regulations have played positive roles in reducing air pollution emissions and maintaining the sustainable development of the atmospheric environment in Heilongjiang.

(2) In accordance with national and local regulations, Heilongjiang has established a strict environmental accountability mechanism to give political sanctions and economic penalties to units and individuals that are not effective in preventing and controlling air pollution, which urges government officials and enterprises to attach great importance to the sustainable development of the atmospheric environment. In early 2018, the provincial government reproached 65 civil servants, including eight cadres at the departmental level and 39 at the sectional level, who were are directly responsible for the poor effectiveness of air pollution prevention and control in October 2017. Among 
them, 45 were given Party and administrative discipline, and 17 were conducted admonition talks. At the same time, the Provincial Agricultural Commission was ordered to make a written inspection to the provincial government [84].

(3) Heilongjiang has focused on controlling major air pollution sources such as coal-fired heating and biomass burning emissions in winter and adopted new technologies for pollution source grid monitoring and straw resource utilization. By the end of 2015, the comprehensive utilization rate of straw in the province exceeded $80 \%$, which effectively reduced atmospheric pollution [82].

\section{Conclusions}

This paper has adopted a new method that can determine the weight more objectively. First, this paper has constructed a PSR Model for the sustainability evaluation of the atmospheric environment of Northeast China as well as an air quality evaluation system consisting of 17 indicators. After this paper obtained the weights by using the rough set method, it further introduced the entropy weight method to make up for the flaws of the rough set method, and effectively solved the issue of large differences in evaluation results by different weighting methods under the rough set method, thus improving the accuracy of the results. This paper obtained the data on changes in the atmospheric environment of the three Northeast provinces from 2009 to 2017. Finally, by consolidating the data of the three provinces, this paper obtained the evaluation result of the atmospheric environment sustainability in Northeast China, which showed that the sustainability level of the atmospheric environment in Northeast China provinces first improved, and then worsened, with the atmospheric environment sustainability level reaching the highest level of 0.9275 in 2014, while dropping to the lowest level of 0.6027 in 2017. In Northeast China, Heilongiiang Province has done the best in the sustainable development of the atmospheric environment. From 2009 to 2017, the sustainability level of Northeast China's atmospheric environment has risen at first but then declined and achieved the best level in 2014.

The research results of this paper have good applicability to the sustainable development of China's atmospheric environment. On the one hand, this paper has obtained a more complete evaluation on the actual sustainability level of the atmospheric environment based on the existing data. The main feature of this study is that it uses the rough set method to calculate the weight of each condition attribute and introduces the entropy weight method to obtain an objective evaluation of the data based on discrete values. On the other hand, this paper has combined the entropy weight method with the rough set method to make up for the flaws of the rough set method and effectively makes use of the advantages of the two methods. The two methods supplement each other and lead to more accurate conclusions regarding the development sustainability of the atmospheric environment. This paper uses the entropy value to solve the problem of inconsistent data under different weighting methods and has innovated a model for atmospheric sustainable development studies as well as enriched the literature on atmospheric environment and sustainable development. Therefore, compared with the previous research, the advantages and applicability of this paper are mainly reflected in:

1. The analysis and calculation of the pressure layer, state layer and response layer. This paper reflects the various factors affecting the sustainable development of atmospheric environment more comprehensively, and provides a more scientific and complete basis for the future sustainable development policies.

2. As far as the research method is concerned, the entropy weight method is used to make up for the shortcomings of the rough set method. The problem of difference in evaluation results caused by using rough set method alone is effectively solved (see Table 5), so that calculation accuracy is optimized.

3. China is vast in territory, and the sources and effects of air pollution are not exactly the same everywhere. By comparing and analyzing the impacts of various factors affecting the sustainable development of the atmospheric environment on different provinces in the same region, this paper could help different regions of China (such as the Yangtze River Delta, Pearl River Delta, etc.) to analyze their own atmospheric environmental impact factors more effectively. 
Based on the evaluation results, this paper has proposed the following suggestions in order for the atmospheric environment of the Northeast region to maintain sustainable development:

1. Develop relevant technologies to improve energy efficiency and reduce waste and pollutant emissions. Meanwhile, establish an incentive program and punishment policy for technology-based enterprises to encourage the research and development as well as application of high-quality technology.

2. Increase investment in industrial pollution control, establish a systematized industrial pollution and waste treatment system, and process different types of pollutants by category. Establish relevant laws and regulations, strictly limit and monitor the pollution emission quota of different production units and enhance law enforcement efforts to crack down on illegal pollution behavior.

3. Further adjust and optimize the industrial structure by lifting the proportion of the service industry in economic development and advancing the transformation and upgrading of the secondary industry; gradually phase out heavily polluting enterprises.

4. The local government of Northeast provinces should also actively encourage and advocate for people to use clean energy and reduce the use of traditional energy. The local government should further enhance the public's environmental awareness [85], and establish an air quality management system in accordance with the concepts of sustainable development with the participation of the public in order to truly realize the "revitalization of the old industrial base in Northeast China".

Author Contributions: Conceptualization, Y.L. and G.Y.; Methodology, M.S.; Software, G.Y.; Validation, Y.L., G.Y. and Q.Z.; Formal Analysis, M.S.; Investigation, Q.Z.; Resources, J.L.; Data Curation, M.S.; Writing-Original Draft Preparation, Y.L.; Writing-Review and Editing, M.S.; Visualization, G.Y.; Supervision, J.L.; Project Administration, Y.L.

Funding: This research received no external funding.

Conflicts of Interest: The authors declare no conflict of interest.

\section{Appendix A Calculation Results by the Three Different Methods for Each Province in Northeast China}

Table A1. Comparison of comprehensive values calculated by different methods for Heilongjiang.

\begin{tabular}{ccccc}
\hline \begin{tabular}{c} 
The Element $\begin{array}{c}\text { Layer } \\
\text { The Pressure Layer }\end{array}$ \\
\cline { 2 - 5 }
\end{tabular} & Year & $\begin{array}{c}\text { The Entropy } \\
\text { Weight Method }\end{array}$ & $\begin{array}{c}\text { The Rough Set } \\
\text { Method }\end{array}$ & $\begin{array}{c}\text { Rough Set + Entropy } \\
\text { Weight Method }\end{array}$ \\
\cline { 2 - 5 } & 2009 & 0.8541 & 0.7277 & 0.8312 \\
\cline { 2 - 5 } & 2010 & 0.7441 & 0.7259 & 0.8248 \\
\hline 2011 & 0.8253 & 0.7698 & 0.8810 \\
\hline 2013 & 0.7355 & 0.6947 & 0.8000 \\
\hline & 2014 & 0.7490 & 0.7143 & 0.8162 \\
\hline 2015 & 0.8480 & 0.7736 & 0.8737 \\
\hline 2016 & 0.4321 & 0.6049 & 0.6996 \\
\hline 2009 & 0.4223 & 0.4541 & 0.5118 \\
\hline 2010 & 0.2802 & 0.2848 & 0.3320 \\
\hline 2011 & 0.2978 & 0.3164 & 0.3423 \\
\hline 2012 & 0.3399 & 0.2491 & 0.2798 \\
\hline 2013 & 0.4399 & 0.4173 & 0.4551 \\
\hline 2014 & 0.4805 & 0.4096 & 0.4523 \\
\hline 2015 & 0.5015 & 0.4349 & 0.4811 \\
\hline 2016 & 0.4858 & 0.5482 & 0.5972 \\
\hline 2017 & 0.4005 & 0.4646 & 0.5147 \\
\hline & 0.5748 & 0.4534 & 0.5164 \\
\hline & & 0.4524 & 0.5162 \\
\hline
\end{tabular}


Table A1. Cont.

\begin{tabular}{|c|c|c|c|c|}
\hline $\begin{array}{l}\text { The Element } \\
\text { Layer }\end{array}$ & Year & $\begin{array}{c}\text { The Entropy } \\
\text { Weight Method }\end{array}$ & $\begin{array}{c}\text { The Rough Set } \\
\text { Method }\end{array}$ & $\begin{array}{l}\text { Rough Set + Entropy } \\
\text { Weight Method }\end{array}$ \\
\hline \multirow{9}{*}{$\begin{array}{c}\text { The Response } \\
\text { Layer }\end{array}$} & 2009 & 0.5419 & 0.3788 & 0.3680 \\
\hline & 2010 & 0.2241 & 0.3162 & 0.3089 \\
\hline & 2011 & 0.2706 & 0.2277 & 0.2108 \\
\hline & 2012 & 0.2022 & 0.3053 & 0.2977 \\
\hline & 2013 & 0.7917 & 0.7251 & 0.7017 \\
\hline & 2014 & 1.0193 & 0.9406 & 0.9290 \\
\hline & 2015 & 0.5652 & 0.4886 & 0.4666 \\
\hline & 2016 & 0.5460 & 0.6186 & 0.5958 \\
\hline & 2017 & 0.3421 & 0.3951 & 0.3896 \\
\hline \multirow{9}{*}{$\begin{array}{l}\text { The Sustainable } \\
\text { Layer }\end{array}$} & 2009 & 0.5670 & 0.2794 & 0.4556 \\
\hline & 2010 & 0.5161 & 0.3241 & 0.4454 \\
\hline & 2011 & 0.5873 & 0.4156 & 0.5912 \\
\hline & 2012 & 0.5710 & 0.4463 & 0.5815 \\
\hline & 2013 & 0.5674 & 0.3967 & 0.6110 \\
\hline & 2014 & 0.7953 & 0.5237 & 0.7278 \\
\hline & 2015 & 0.6302 & 0.4894 & 0.6869 \\
\hline & 2016 & 0.4433 & 0.4326 & 0.4624 \\
\hline & 2017 & 0.5015 & 0.5720 & 0.5493 \\
\hline
\end{tabular}

Table A2. Comparison of comprehensive values calculated by different methods for Jilin.

\begin{tabular}{ccccc}
\hline $\begin{array}{c}\text { The Element } \\
\text { Layer }\end{array}$ & Year & $\begin{array}{c}\text { The Entropy } \\
\text { Weight Method }\end{array}$ & $\begin{array}{c}\text { The Rough Set } \\
\text { Method }\end{array}$ & $\begin{array}{c}\text { Rough Set + Entropy } \\
\text { Weight Method }\end{array}$ \\
\hline & 2009 & 0.5787 & 0.8304 & 0.7045 \\
\cline { 2 - 5 } The Pressure Layer & 2010 & 0.5291 & 0.7724 & 0.6507 \\
\cline { 2 - 5 } & 2011 & 0.5639 & 0.8408 & 0.7024 \\
\cline { 2 - 5 } & 2012 & 0.5307 & 0.7932 & 0.6620 \\
\hline 2013 & 0.5203 & 0.7740 & 0.6471 \\
\hline 2014 & 0.6030 & 0.8412 & 0.7221 \\
\hline 2015 & 0.5501 & 0.7781 & 0.6641 \\
\hline 2016 & 0.3501 & 0.4873 & 0.4187 \\
\hline 2017 & 0.3017 & 0.4121 & 0.3569 \\
\hline 2009 & 0.2179 & 0.2761 & 0.2347 \\
\hline 2010 & 0.2635 & 0.3322 & 0.2831 \\
\hline 2011 & 0.3164 & 0.4018 & 0.3413 \\
\hline 2012 & 0.3517 & 0.4488 & 0.3799 \\
\hline 2013 & 0.3832 & 0.4884 & 0.4132 \\
\hline 2014 & 0.4023 & 0.5143 & 0.4343 \\
\hline 2015 & 0.4014 & 0.5168 & 0.4351 \\
\hline 2016 & 0.3179 & 0.4819 & 0.3784 \\
\hline 2017 & 0.3348 & 0.4993 & 0.3948 \\
\hline
\end{tabular}


Table A2. Cont.

\begin{tabular}{|c|c|c|c|c|}
\hline $\begin{array}{l}\text { The Element } \\
\text { Layer }\end{array}$ & Year & $\begin{array}{c}\text { The Entropy } \\
\text { Weight Method }\end{array}$ & $\begin{array}{c}\text { The Rough Set } \\
\text { Method }\end{array}$ & $\begin{array}{l}\text { Rough Set + Entropy } \\
\text { Weight Method }\end{array}$ \\
\hline \multirow{9}{*}{$\begin{array}{l}\text { The Response } \\
\text { Layer }\end{array}$} & 2009 & 0.4360 & 0.3566 & 0.3826 \\
\hline & 2010 & 0.2824 & 0.2236 & 0.2643 \\
\hline & 2011 & 0.2958 & 0.2230 & 0.2168 \\
\hline & 2012 & 0.2298 & 0.1773 & 0.2116 \\
\hline & 2013 & 0.7305 & 0.6101 & 0.5560 \\
\hline & 2014 & 0.9405 & 0.7977 & 0.8637 \\
\hline & 2015 & 0.5843 & 0.4679 & 0.4654 \\
\hline & 2016 & 0.5711 & 0.4668 & 0.4176 \\
\hline & 2017 & 0.3891 & 0.3223 & 0.3717 \\
\hline \multirow{9}{*}{$\begin{array}{l}\text { The Sustainable } \\
\text { Layer }\end{array}$} & 2009 & 0.1625 & 0.6836 & 0.4310 \\
\hline & 2010 & 0.2574 & 0.6138 & 0.3955 \\
\hline & 2011 & 0.1781 & 0.6455 & 0.5787 \\
\hline & 2012 & 0.2459 & 0.6007 & 0.5277 \\
\hline & 2013 & 0.1162 & 0.6836 & 0.6509 \\
\hline & 2014 & 0.2937 & 0.8182 & 0.7775 \\
\hline & 2015 & 0.1504 & 0.6749 & 0.6223 \\
\hline & 2016 & 0.3844 & 0.4363 & 0.3958 \\
\hline & 2017 & 0.5014 & 0.3675 & 0.4527 \\
\hline
\end{tabular}

Table A3. Comparison of comprehensive values calculated by different methods for Liaoning.

\begin{tabular}{|c|c|c|c|c|}
\hline $\begin{array}{c}\text { The Element } \\
\text { Layer }\end{array}$ & Year & $\begin{array}{c}\text { The Entropy } \\
\text { Weight Method }\end{array}$ & $\begin{array}{c}\text { The Rough Set } \\
\text { Method }\end{array}$ & $\begin{array}{l}\text { Rough Set + Entropy } \\
\text { Weight Method }\end{array}$ \\
\hline \multirow{9}{*}{ The Pressure Layer } & 2009 & 0.6649 & 0.7194 & 0.5918 \\
\hline & 2010 & 0.5201 & 0.5750 & 0.4549 \\
\hline & 2011 & 0.6700 & 0.7353 & 0.6026 \\
\hline & 2012 & 0.5629 & 0.6250 & 0.4997 \\
\hline & 2013 & 0.5923 & 0.6518 & 0.5299 \\
\hline & 2014 & 0.5966 & 0.6442 & 0.5176 \\
\hline & 2015 & 0.6447 & 0.6922 & 0.5740 \\
\hline & 2016 & 0.4519 & 0.4791 & 0.4060 \\
\hline & 2017 & 0.2979 & 0.3183 & 0.2573 \\
\hline \multirow{9}{*}{ The State Layer } & 2009 & 0.3147 & 0.3227 & 0.2804 \\
\hline & 2010 & 0.2814 & 0.2903 & 0.2397 \\
\hline & 2011 & 0.4655 & 0.4774 & 0.4158 \\
\hline & 2012 & 0.5076 & 0.5217 & 0.4525 \\
\hline & 2013 & 0.4985 & 0.5137 & 0.4383 \\
\hline & 2014 & 0.4017 & 0.4182 & 0.3386 \\
\hline & 2015 & 0.5032 & 0.5211 & 0.4406 \\
\hline & 2016 & 0.4505 & 0.4927 & 0.4091 \\
\hline & 2017 & 0.5008 & 0.5421 & 0.4563 \\
\hline
\end{tabular}


Table A3. Cont.

\begin{tabular}{|c|c|c|c|c|}
\hline $\begin{array}{l}\text { The Element } \\
\text { Layer }\end{array}$ & Year & $\begin{array}{c}\text { The Entropy } \\
\text { Weight Method }\end{array}$ & $\begin{array}{c}\text { The Rough Set } \\
\text { Method }\end{array}$ & $\begin{array}{c}\text { Rough Set + Entropy } \\
\text { Weight Method }\end{array}$ \\
\hline \multirow{9}{*}{$\begin{array}{l}\text { The Response } \\
\text { Layer }\end{array}$} & 2009 & 0.5174 & 0.4573 & 0.4277 \\
\hline & 2010 & 0.2486 & 0.2045 & 0.1937 \\
\hline & 2011 & 0.3711 & 0.3268 & 0.3013 \\
\hline & 2012 & 0.2556 & 0.2181 & 0.2102 \\
\hline & 2013 & 0.6836 & 0.5979 & 0.5163 \\
\hline & 2014 & 0.8349 & 0.7132 & 0.6495 \\
\hline & 2015 & 0.5190 & 0.4393 & 0.3890 \\
\hline & 2016 & 0.5600 & 0.4905 & 0.4256 \\
\hline & 2017 & 0.3785 & 0.3232 & 0.3046 \\
\hline \multirow{9}{*}{$\begin{array}{l}\text { The Sustainable } \\
\text { Layer }\end{array}$} & 2009 & 0.3605 & 0.5470 & 0.3951 \\
\hline & 2010 & 0.4691 & 0.5913 & 0.4575 \\
\hline & 2011 & 0.3333 & 0.4802 & 0.3908 \\
\hline & 2012 & 0.4482 & 0.5543 & 0.4677 \\
\hline & 2013 & 0.3444 & 0.5244 & 0.4417 \\
\hline & 2014 & 0.5337 & 0.6879 & 0.5885 \\
\hline & 2015 & 0.3522 & 0.5181 & 0.4301 \\
\hline & 2016 & 0.5235 & 0.5173 & 0.4584 \\
\hline & 2017 & 0.4586 & 0.3693 & 0.3572 \\
\hline
\end{tabular}

\section{References}

1. Barbier, E.B. The concept of sustainable economic development. Environ. Conserv. 1987, 14, $101-110$. [CrossRef]

2. Spangenberg, J.H. Institutional sustainability indicators: an analysis of the institutions in Agenda 21 and a draft set of indicators for monitoring their effectivity. Sustain. Dev. 2002, 10, 103-115. [CrossRef]

3. State Council of the People's Republic of China. The 21st Century Agenda of China: White Paper on Population, Environment and Development in the 21st Century; China Environmental Science Press: Beijing, China, 1994.

4. Liu, L. Sustainability: Living within One's Own Ecological Means. Sustainability 2009, 1, 1412-1430. [CrossRef]

5. Yang, W.; Li, L. Energy Efficiency, Ownership Structure, and Sustainable Development: Evidence from China. Sustainability 2017, 9, 912. [CrossRef]

6. Li, L.; Yang, W. Total Factor Efficiency Study on China's Industrial Coal Input and Wastewater Control with Dual Target Variables. Sustainability 2018, 10, 2121. [CrossRef]

7. Novas, N.; Gázquez, J.A.; MacLennan, J.; García, R.M.; Fernández-Ros, M.; Manzano-Agugliaro, F. A real-time underground environment monitoring system for sustainable tourism of caves. J. Clean. Prod. 2017, 142, 2707-2721. [CrossRef]

8. Opoku, A. Biodiversity and the built environment: Implications for the Sustainable Development Goals (SDGs). Resour. Conserv. Recycl. 2019, 141, 1-7. [CrossRef]

9. Yang, W.; Li, L. Efficiency evaluation of industrial waste gas control in China: A study based on data envelopment analysis (DEA) model. J. Clean. Prod. 2018, 179, 1-11. [CrossRef]

10. Santillán Soto, N.; García Cueto, O.R.; Lambert Arista, A.A.; Ojeda Benítez, S.; Cruz Sotelo, S.E. Comparative Analysis of Two Urban Microclimates: Energy Consumption and Greenhouse Gas Emissions. Sustainability 2019, 11, 2045. [CrossRef]

11. Yeh, H.F.; Hsu, H.L. Using the Markov Chain to Analyze Precipitation and Groundwater Drought Characteristics and Linkage with Atmospheric Circulation. Sustainability 2019, 11, 1817. [CrossRef]

12. Yang, W.; Yuan, G.; Han, J. Is China's air pollution control policy effective? Evidence from Yangtze River Delta cities. J. Clean. Prod. 2019, 220, 110-133. [CrossRef] 
13. Rodriguez, Y.R. Great Smog of London. In Encyclopedia of Toxicology, 3rd ed.; Wexler, P., Ed.; Academic Press: Oxford, UK, 2014; pp. 796-797. ISBN 978-0-12-386455-0.

14. Ashraf, A.; Butt, A.; Khalid, I.; Alam, R.U.; Ahmad, S.R. Smog analysis and its effect on reported ocular surface diseases: A case study of 2016 smog event of Lahore. Atmos. Environ. 2019, 198, 257-264. [CrossRef]

15. Yuan, G.; Yang, W. Evaluating China's Air Pollution Control Policy with Extended AQI Indicator System: Example of the Beijing-Tianjin-Hebei Region. Sustainability 2019, 11, 939. [CrossRef]

16. Zhang, D.; Lei, L.; Ji, Q.; Kutan, A.M. Economic policy uncertainty in the US and China and their impact on the global markets. Econ. Model. 2019, 79, 47-56. [CrossRef]

17. Xu, X.; Li, D.D.; Zhao, M. "Made in China" matters: Integration of the global labor market and the global labor share decline. China Econ. Rev. 2018, 52, 16-29. [CrossRef]

18. Yang, W.; Li, L. Analysis of Total Factor Efficiency of Water Resource and Energy in China: A Study Based on DEA-SBM Model. Sustainability 2017, 9, 1316. [CrossRef]

19. Springer, C.; Evans, S.; Lin, J.; Roland-Holst, D. Low carbon growth in China: The role of emissions trading in a transitioning economy. Appl. Energy 2019, 235, 1118-1125. [CrossRef]

20. Wang, Y.; Wang, N. The role of the port industry in China's national economy: An input-output analysis. Transp. Policy 2019, 78, 1-7. [CrossRef]

21. Yang, W.; Li, L. Efficiency Evaluation and Policy Analysis of Industrial Wastewater Control in China. Energies 2017, 10, 1201. [CrossRef]

22. National Bureau of Statistics of China. China Statistical Yearbook, 2017-2018; China Statistic Press: Beijing, China, 2018.

23. Wang, J.; Zhang, X.; Yang, Q.; Zhang, K.; Zheng, Y.; Zhou, G. Pollution characteristics of atmospheric dustfall and heavy metals in a typical inland heavy industry city in China. J. Environ. Sci. 2018, 71, $283-291$. [CrossRef]

24. Zhang, Q. Energy and resource conservation and air pollution abatement in China's iron and steel industry. Resour. Conserv. Recycl. 2019, 147, 67-84. [CrossRef]

25. Yang, H.; Tao, W.; Liu, Y.; Qiu, M.; Liu, J.; Jiang, K.; Yi, K.; Xiao, Y.; Tao, S. The contribution of the Beijing, Tianjin and Hebei region's iron and steel industry to local air pollution in winter. Environ. Pollut. 2019, 245, 1095-1106. [CrossRef] [PubMed]

26. Xie, L.; Flynn, A.; Tan-Mullins, M.; Cheshmehzangi, A. The making and remaking of ecological space in China: The political ecology of Chongming Eco-Island. Political Geogr. 2019, 69, 89-102. [CrossRef]

27. Dai, L.; Li, S.; Zhou, W.; Qi, L.; Zhou, L.; Wei, Y.; Li, J.; Shao, G.; Yu, D. Opportunities and challenges for the protection and ecological functions promotion of natural forests in China. For. Ecol. Manag. 2018, 410, 187-192. [CrossRef]

28. Yang, Q.; Liu, G.; Hao, Y.; Coscieme, L.; Zhang, J.; Jiang, N.; Casazza, M.; Giannetti, B.F. Quantitative analysis of the dynamic changes of ecological security in the provinces of China through emergy-ecological footprint hybrid indicators. J. Clean. Prod. 2018, 184, 678-695. [CrossRef]

29. Zhang, Q.; Liao, H.; Hao, Y. Does one path fit all? An empirical study on the relationship between energy consumption and economic development for individual Chinese provinces. Energy 2018, 150, 527-543. [CrossRef]

30. Cheng, X.; Li, N.; Mu, H.; Guo, Y.; Jiang, Y. Study on Total-Factor Energy Efficiency in Three Provinces of Northeast China Based on SBM Model. Energy Procedia 2018, 152, 131-136. [CrossRef]

31. Zhen, G.; Qieyi, L.; Xiaoxu, W. On Development Model based on Intra-county Cyclic Economy under Low-carbon Economy for Northeast China. Energy Procedia 2011, 5, 1553-1557. [CrossRef]

32. Zhang, C.; Liu, Y.; Qiao, H. An empirical study on the spatial distribution of the population, economy and water resources in Northeast China. Phys. Chem. Earth Parts A/B/C 2015, 79-82, 93-99. [CrossRef]

33. Zhang, P.; Yuan, H.; Bai, F.; Tian, X.; Shi, F. How do carbon dioxide emissions respond to industrial structural transitions? Empirical results from the northeastern provinces of China. Struct. Chang. Econ. Dyn. 2018, 47, 145-154. [CrossRef]

34. Zeng, X.-W.; Qian, Z.M.; Vaughn, M.G.; Nelson, E.J.; Dharmage, S.C.; Bowatte, G.; Perret, J.; Chen, D.-H.; Ma, H.; Lin, S.; et al. Positive association between short-term ambient air pollution exposure and children blood pressure in China-Result from the Seven Northeast Cities (SNEC) study. Environ. Pollut. 2017, 224, 698-705. [CrossRef] [PubMed] 
35. Li, X.; Sun, Y.; An, Y.; Wang, R.; Lin, H.; Liu, M.; Li, S.; Ma, M.; Xiao, C. Air pollution during the winter period and respiratory tract microbial imbalance in a healthy young population in Northeastern China. Environ. Pollut. 2019, 246, 972-979. [CrossRef] [PubMed]

36. Yin, S.; Wang, X.; Zhang, X.; Zhang, Z.; Xiao, Y.; Tani, H.; Sun, Z. Exploring the effects of crop residue burning on local haze pollution in Northeast China using ground and satellite data. Atmos. Environ. 2019, 199, 189-201. [CrossRef]

37. National Bureau of Statistics of China. China Statistical Yearbook, 2011-2017; China Statistic Press: Beijing, China, 2018.

38. Lai, X.; Liu, J.; Georgiev, G. Low carbon technology integration innovation assessment index review based on rough set theory-An evidence from construction industry in China. J. Clean. Prod. 2016, 126, 88-96. [CrossRef]

39. Xue, Y.; Chen, Y.; Hu, Y.; Chen, H. Fuzzy Rough Set algorithm with Binary Shuffled Frog-Leaping (BSFL-FRSA): An innovative approach for identifying main drivers of carbon exchange in temperate deciduous forests. Ecol. Indic. 2017, 83, 41-52. [CrossRef]

40. Zhao, X.; Qi, Q.; Li, R. The establishment and application of fuzzy comprehensive model with weight based on entropy technology for air quality assessment. Procedia Eng. 2010, 7, 217-222. [CrossRef]

41. Chen, L.; Gao, S.; Zhang, H.; Sun, Y.; Ma, Z.; Vedal, S.; Mao, J.; Bai, Z. Spatiotemporal modeling of PM2.5 concentrations at the national scale combining land use regression and Bayesian maximum entropy in China. Environ. Int. 2018, 116, 300-307. [CrossRef] [PubMed]

42. Liu, W.; Jiao, F.; Ren, L.; Xu, X.; Wang, J.; Wang, X. Coupling coordination relationship between urbanization and atmospheric environment security in Jinan City. J. Clean. Prod. 2018, 204, 1-11. [CrossRef]

43. Ou, C.; Liu, W. Developing a sustainable indicator system based on the pressure-state-response framework for local fisheries: A case study of Gungliau, Taiwan. Ocean Coast. Manag. 2010, 53, 289-300. [CrossRef]

44. Guo, M.; Bu, Y.; Cheng, J.; Jiang, Z. Natural Gas Security in China: A Simulation of Evolutionary Trajectory and Obstacle Degree Analysis. Sustainability 2018, 11, 96. [CrossRef]

45. Zhao, Y.W.; Zhou, L.Q.; Dong, B.Q.; Dai, C. Health assessment for urban rivers based on the pressure, state and response framework-A case study of the Shiwuli River. Ecol. Indic. 2019, 99, 324-331. [CrossRef]

46. Li, S.; Li, R. Evaluating Energy Sustainability Using the Pressure-State-Response and Improved Matter-Element Extension Models: Case Study of China. Sustainability 2019, 11, 290. [CrossRef]

47. Zhang, X.C.; Ma, C.; Zhan, S.F.; Chen, W.P. Evaluation and simulation for ecological risk based on emergy analysis and Pressure-State-Response Model in a coastal city, China. Procedia Environ. Sci. 2012, 13, $221-231$. [CrossRef]

48. Huang, Z.; Xu, M.; Chen, W.; Lin, X.; Cao, C.; Singh, R.P. Postseismic Restoration of the Ecological Environment in the Wenchuan Region Using Satellite Data. Sustainability 2018, 10, 3990. [CrossRef]

49. Neri, A.C.; Dupin, P.; Sánchez, L.E. A pressure-state-response approach to cumulative impact assessment. J. Clean. Prod. 2016, 126, 288-298. [CrossRef]

50. Deng, M.; Chen, J.; Huang, J.; Niu, W. Agricultural Drought Risk Evaluation Based on an Optimized Comprehensive Index System. Sustainability 2018, 10, 3465. [CrossRef]

51. Bai, X.; Tang, J. Ecological Security Assessment of Tianjin by PSR Model. Procedia Environ. Sci. 2010, 2, 881-887. [CrossRef]

52. Chen, Y.; Wang, P.; Zhong, B.; Ouyang, G.; Bai, B.; Du, J. Coarse-to-fine visual tracking with PSR and scale driven expert-switching. Neurocomputing 2018, 275, 1456-1467. [CrossRef]

53. Sun, B.; Tang, J.; Yu, D.; Song, Z.; Wang, P. Ecosystem health assessment: A PSR analysis combining AHP and FCE methods for Jiaozhou Bay, China1. Ocean Coast. Manag. 2019, 168, 41-50. [CrossRef]

54. Grossman, G.M.; Krueger, A.B. Economic Growth and the Environment. Q. J. Econ. 1995, 110, $353-377$. [CrossRef]

55. Guo, Q.; Wang, J.; Yin, H.; Zhang, G. A comprehensive evaluation model of regional atmospheric environment carrying capacity: Model development and a case study in China. Ecol. Indic. 2018, 91, 259-267. [CrossRef]

56. Wang, Q.; Li, S.; Li, R. Evaluating water resource sustainability in Beijing, China: Combining PSR model and matter-element extension method. J. Clean. Prod. 2019, 206, 171-179. [CrossRef]

57. National Bureau of Statistics of China. China Statistical Yearbook, 2009-2017; China Statistic Press: Beijing, China, 2018. 
58. Liu, F.; Zhao, S.; Weng, M.; Liu, Y. Fire risk assessment for large-scale commercial buildings based on structure entropy weight method. Saf. Sci. 2017, 94, 26-40. [CrossRef]

59. Xu, H.; Ma, C.; Lian, J.; Xu, K.; Chaima, E. Urban flooding risk assessment based on an integrated k-means cluster algorithm and improved entropy weight method in the region of Haikou, China. J. Hydrol. 2018, 563, 975-986. [CrossRef]

60. Järvinen, J.; Kovács, L.; Radeleczki, S. Defining rough sets using tolerances compatible with an equivalence. Inf. Sci. 2019. [CrossRef]

61. Han, S.E. Roughness measures of locally finite covering rough sets. Int. J. Approx. Reason. 2019, 105, 368-385. [CrossRef]

62. Fang, Y.; Min, F. Cost-sensitive approximate attribute reduction with three-way decisions. Int. J. Approx. Reason. 2019, 104, 148-165. [CrossRef]

63. Kunz, M.; Puchta, A.; Groll, S.; Fuchs, L.; Pernul, G. Attribute quality management for dynamic identity and access management. J. Inf. Secur. Appl. 2019, 44, 64-79. [CrossRef]

64. Wang, Q.; Qian, Y.; Liang, X.; Guo, Q.; Liang, J. Local neighborhood rough set. Knowl.-Based Syst. 2018, 153, 53-64. [CrossRef]

65. Han, S.E. Covering rough set structures for a locally finite covering approximation space. Inf. Sci. 2019, 480, 420-437. [CrossRef]

66. Zhang, L.; Jin, Z.; Zheng, Y.; Jiang, R. Mechanical Product Ecological Design Knowledge Reduction Based on Rough Set. Procedia CIRP 2019, 80, 33-38. [CrossRef]

67. Wang, C.; Huang, Y.; Shao, M.; Fan, X. Fuzzy rough set-based attribute reduction using distance measures. Knowl.-Based Syst. 2019, 164, 205-212. [CrossRef]

68. Zhang, S.; Xu, S.; Zhang, W.; Yu, D.; Chen, K. A hybrid approach combining an extended BBO algorithm with an intuitionistic fuzzy entropy weight method for QoS-aware manufacturing service supply chain optimization. Neurocomputing 2018, 272, 439-452. [CrossRef]

69. Zhou, M.; Liu, X.; Yang, J.; Chen, Y.; Wu, J. Evidential reasoning approach with multiple kinds of attributes and entropy-based weight assignment. Knowl.-Based Syst. 2019, 163, 358-375. [CrossRef]

70. Zhou, J.; Chen, L.; Chen, C.L.P.; Zhang, Y.; Li, H.-X. Fuzzy clustering with the entropy of attribute weights. Neurocomputing 2016, 198, 125-134. [CrossRef]

71. Wang, K.; Wang, Y. Entropy numbers of functions on [-1,1] with Jacobi weights. J. Math. Anal. Appl. 2017, 445, 985-997. [CrossRef]

72. Jing, Y.; Li, T.; Fujita, H.; Wang, B.; Cheng, N. An incremental attribute reduction method for dynamic data mining. Inf. Sci. 2018, 465, 202-218. [CrossRef]

73. Konecny, J.; Krajča, P. On attribute reduction in concept lattices: The polynomial time discernibility matrix-based method becomes the CR-method. Inf. Sci. 2019, 491, 48-62. [CrossRef]

74. Chen, J.; Mi, J.; Xie, B.; Lin, Y. A fast attribute reduction method for large formal decision contexts. Int. J. Approx. Reason. 2019, 106, 1-17. [CrossRef]

75. Qiu, Y. Management Decision Entropy and Its Application; China Electric Power Press: Beijing, China, 2011.

76. Virto, L.R. A preliminary assessment of the indicators for Sustainable Development Goal (SDG) 14 "Conserve and sustainably use the oceans, seas and marine resources for sustainable development". Mar. Policy 2018, 98, 47-57. [CrossRef]

77. Kılkış, Ş.; Krajačić, G.; Duić, N.; Rosen, M.A.; Al-Nimr, M.A. Advancements in sustainable development of energy, water and environment systems. Energy Convers. Manag. 2018, 176, 164-183. [CrossRef]

78. Ye, J. Multicriteria fuzzy decision-making method using entropy weights-based correlation coefficients of interval-valued intuitionistic fuzzy sets. Appl. Math. Model. 2010, 34, 3864-3870. [CrossRef]

79. Ji, Y.; Huang, G.H.; Sun, W. Risk assessment of hydropower stations through an integrated fuzzy entropy-weight multiple criteria decision making method: A case study of the Xiangxi River. Expert Syst. Appl. 2015, 42, 5380-5389. [CrossRef]

80. Cui, Y.; Feng, P.; Jin, J.; Liu, L. Water Resources Carrying Capacity Evaluation and Diagnosis Based on Set Pair Analysis and Improved the Entropy Weight Method. Entropy 2018, 20, 359. [CrossRef]

81. Heilongjiang Provincial Government. Implementation Rules of Air Pollution Prevention Action Plan in Heilongjiang; Heilongjiang Provincial Government: Harbin, Heilongjiang, China, 2014.

82. Heilongiiang Provincial Government. Special Action Plan for Air Pollution Prevention and Control in Heilongjiang Province, 2016-2018; Heilongjiang Provincial Government: Harbin, Heilongjiang, China, 2016. 
83. The 12th People's Congress of Heilongjiang Province. Air Pollution Prevention and Control Regulations of Heilongjiang Province; People's Congress of Heilongjiang Province: Harbin, Heilongjiang, China, 2017.

84. Xinhua Net Ministry of Ecology and Environment: 65 People in 4 Cities of Heilongjiang Province Are Reproaches for Their Ineffectively Control Haze. Available online: http://www.xinhuanet.com/2018-05/29/c_ 129882781.htm (accessed on 1 July 2019).

85. Yang, Y.; Yang, W. Does Whistleblowing Work for Air Pollution Control in China? A Study Based on Three-party Evolutionary Game Model under Incomplete Information. Sustainability 2019, 11, 324. [CrossRef]

(C) 2019 by the authors. Licensee MDPI, Basel, Switzerland. This article is an open access article distributed under the terms and conditions of the Creative Commons Attribution (CC BY) license (http://creativecommons.org/licenses/by/4.0/). 